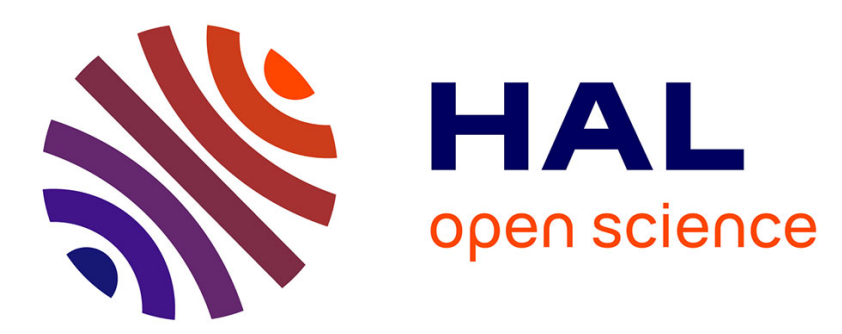

\title{
Assessment of variable separation for finite element modeling of free edge effect for composite plates
}

\author{
P. Vidal, L. Gallimard, O. Polit
}

\section{To cite this version:}

P. Vidal, L. Gallimard, O. Polit. Assessment of variable separation for finite element modeling of free edge effect for composite plates. Composite Structures, 2015, 123, pp.19 - 29. 10.1016/j.compstruct.2014.11.068 . hal-01366905

\section{HAL Id: hal-01366905 https://hal.science/hal-01366905}

Submitted on 8 Jan 2018

HAL is a multi-disciplinary open access archive for the deposit and dissemination of scientific research documents, whether they are published or not. The documents may come from teaching and research institutions in France or abroad, or from public or private research centers.
L'archive ouverte pluridisciplinaire HAL, est destinée au dépôt et à la diffusion de documents scientifiques de niveau recherche, publiés ou non, émanant des établissements d'enseignement et de recherche français ou étrangers, des laboratoires publics ou privés. 


\title{
Assessment of variable separation for finite element modeling of free edge effect for composite plates
}

\author{
P. Vidal*, L. Gallimard, O. Polit \\ LEME, EA 4416, Université Paris Ouest, 50 rue de Sèvres, 92410 Ville d'Avray, France
}

\begin{abstract}
A B S T R A C T
This paper deals with the assessment of an approach based on the separation of variables for the modeling of the free edge effect in laminated composite plates. This is of major importance for damage of composite structures. The displacement field is approximated as a sum of separated functions of the in-plane coordinates $x, y$ and the transverse coordinate $z$. This choice yields to an iterative process that consists of solving a 2D and 1D problem successively at each iteration. In the thickness direction, a fourth-order expansion in each layer is considered. For the in-plane description, classical finite element method is used.

Numerical examples involving several representative laminates subjected to uniaxial tension are addressed to show the capability of the present LW method to capture the steep transverse stress gradients occurring in the vicinity of free edges. It is shown that it can provide quasi-3D results less costly than 3D FEM computations.
\end{abstract}

\section{Introduction}

Composite and sandwich structures are widely used in the weight-sensitive industrial applications due to their excellent mechanical properties, especially their high specific stiffness and strength. In this context, they can be subjected to severe mechanical loading. For composite design, accurate knowledge of displacements and stresses is required. So, it is important to take into account transverse shear deformation due to the low ratio of transverse shear modulus to axial modulus, or failure due to delamination. In fact, they can play an important role on the behavior of structures in services, which leads to evaluate precisely their influence on local stress fields in each layer, particularly at the interface between layers.

It is nowadays well established that theoretical models for heterogeneous structures can be classified as follows:

- the Equivalent Single Layer Models (ESL), where the classical Love-Kirchhoff (CLT, [1]), Reissner-Mindlin (FSDT, [2]) and higher-order models (HSDT, [3-6]) can be found for plates. The first one leads to inaccurate results for composites because both transverse and normal strains are neglected. The second

\footnotetext{
* Corresponding author.

E-mail address: philippe.vidal@u-paris10.fr (P. Vidal).
}

one needs a shear correction factor. Moreover, transverse shear and normal stress continuity conditions at the interfaces between layers are violated for all of them.

- the Layer-Wise Models (LW) that aim at overcoming the restriction of the ESL concerning the discontinuity of out-of-plane stresses at the interface between adjacent layers. The reader can refer to the works of Pagano [7] and Reddy [8]. See also [9-11].

According to Reddy [12], the number of unknowns remains independent of the number of constitutive layers in the ESLM, while the same set of variables is used in each layer for the LWM.

Another way for obtaining new models is based on the introduction of interface conditions into higher-order model pertaining to the ESL or to the LW. This permits to reduce the number of unknowns and can be viewed as Zig-Zag models [13-16].

Note that excellent reviews and extensive assessments have been made in the following articles [17-22].

It is known that relevant transverse stresses arise in presence of in-plane stress gradients and in vicinity of material and/or geometric discontinuities. Free-edge effects are typical boundary layer effects where a 3D stress concentration is locally confined in a small region in the vicinity of the free edge [23]. The free-edge effect arising in a composite plate subjected to tensile loads has been extensively studied since the seminal works of Pipes and Pagano $[24,25]$. This configuration can be considered as representative test 
case allowing to discriminate 2D models previously described. We refer the interested reader to the more complete surveys on this topic by Mittelstedt and Becker [26,27] and in the review detailed in [28]. By referring only to the numerical works related to the Pipes-Pagno tests, it seems that two approaches lead to the most accurate results for the local quantities (transverse normal and shear stresses). The first one is based on the generalized plane strain assumption $[29,30]$, but it is limited to cross-ply laminates and particular test cases. The second one employs a LW, as in $[31,32,28]$. But, such approaches suffer from increasing computational costs with the number of layers. Note that further descriptions of main works related to the Pipes-Pagano test will be given in the section dedicated to the numerical tests.

In this work, a promising alternative approach based on the separation of variables could overcome these drawbacks. Interesting features have been shown in the reduction model framework [33]. It has been proposed in [34] with a Navier-type solution for the modeling of composite plates and also used in [35]. The description of the mechanical quantities through the thickness can be easily improved in the presented approach, as shown in [36]. So, the aim of the present paper is to assess this method to capture local effects for laminated structures, and in particular the free-edge effect which is of major interest for the delamination of such structures. This method is based on the separation representation where the displacements are written under the form of a sum of products of bidimensional polynomials of $(x, y)$ and unidimensional polynomials of $z$. A piecewise fourth-order Lagrange polynomial of $z$ is chosen. As far as the variation with respect to the in-plane coordinates is concerned, a 2D eight-node quadrilateral FE is employed. Using this method, each unknown function of $(x, y)$ is classically approximated using one degree of freedom (dof) per node of the mesh and the LW unknown functions of $z$ are global for the whole plate. Finally, the deduced non-linear problem implies the resolution of two linear problems alternatively. This process yields to a 2D and a 1D problems in which the number of unknowns is much smaller than a classical Layerwise approach.

We now outline the remainder of this article. First, the mechanical formulation is given. Then, the principles of the PGD are briefly recalled in the framework of our study. The particular assumption on the displacements yields a non-linear problem. An iterative process is chosen to solve this one. The FE discretization is also described. Numerical evaluations dedicated to the Pipes-Pagano problem are subsequently presented. The study considers symmetric cross-ply, angle-ply and quasi-isotropic laminates. The behavior of the method is first presented and illustrated. Then, it is assessed by comparing with both 3D FEM computations performed with the commercial software Ansys and also with results available in literature. In particular, results of a LW model issued from the Carrera's Unified Formulation are provided. The influence of the numerical layers is also studied. Interesting features to capture the local effect near the free edge can be emphasized.

\section{Reference problem description: the governing equations}

Let us consider a plate occupying the domain $\mathcal{V}=\Omega \times \Omega_{z}$ with $\Omega=[-a, a] \times[-b, b] \Omega_{z}=[-h, h]$ in a Cartesian coordinate $(x, y, z)$. The plate is defined by an arbitrary region $\Omega$ in the $(x, y)$ plane, located at the midplane for $z=0$, and by a constant thickness $2 h$. See Fig. 1.

\subsection{Constitutive relation}

The plate can be made of NC perfectly bonded orthotropic layers. Using matrix notation, the three dimensional constitutive law of the kth layer is given by:

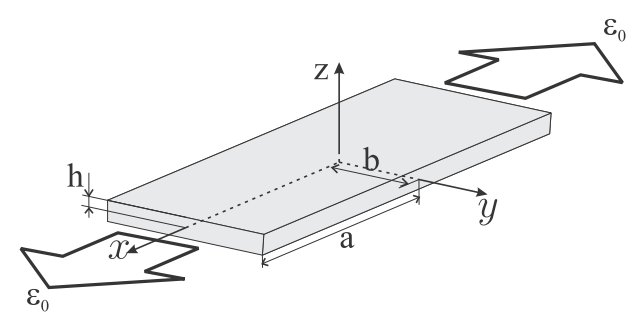

Fig. 1. The Pipes-Pagano problem: composite laminate under uniaxial uniform tensile load and coordinate system.

$$
\left[\begin{array}{c}
\sigma_{11}^{(k)} \\
\sigma_{22}^{(k)} \\
\sigma_{33}^{(k)} \\
\sigma_{23}^{(k)} \\
\sigma_{13}^{(k)} \\
\sigma_{12}^{(k)}
\end{array}\right]=\left[\begin{array}{cccccc}
C_{11}^{(k)} & C_{12}^{(k)} & C_{13}^{(k)} & 0 & 0 & C_{16}^{(k)} \\
& C_{22}^{(k)} & C_{23}^{(k)} & 0 & 0 & C_{26}^{(k)} \\
& & C_{33}^{(k)} & 0 & 0 & C_{36}^{(k)} \\
& & & C_{44}^{(k)} & C_{45}^{(k)} & 0 \\
& & & & C_{55}^{(k)} & 0 \\
& 5 y m & & & & C_{66}^{(k)}
\end{array}\right]\left[\begin{array}{c}
\varepsilon_{11}^{(k)} \\
\varepsilon_{22}^{(k)} \\
\varepsilon_{33}^{(k)} \\
\gamma_{23}^{(k)} \\
\gamma_{13}^{(k)} \\
\gamma_{12}^{(k)}
\end{array}\right]
$$

i.e. $\left[\sigma^{(k)}\right]=\left[C^{(k)}\right]\left[\varepsilon^{(k)}\right]$

where we denote the stress vector $[\sigma]$, the strain vector $[\varepsilon]$ and $C_{i j}^{(k)}$ the three-dimensional stiffness coefficients of the layer $(k)$.

\subsection{The weak form of the boundary value problem}

Using the above matrix notation and for admissible displacement $\delta \vec{u} \in \delta U$, the variational principle is given by:

find $\vec{u} \in U$ (space of admissible displacements) such that

$-\int_{\mathcal{V}}[\varepsilon(\delta \vec{u})]^{T}[\sigma(\vec{u})] d \mathcal{V}+\int_{\mathcal{V}}[\delta u]^{T}[b] d \mathcal{V}+\int_{\partial \mathcal{V}_{F}}[\delta u]^{T}[t] d \partial \mathcal{V}=0, \quad \forall \delta \vec{u} \in \delta U$

where $[b]$ and $[t]$ are the prescribed body and surface forces applied on $\partial \mathcal{V}_{F}$.

\section{Application of the proper generalized method to plate}

In this section, for sake of conciseness, we briefly introduce the application of the variable separation for plate analysis that has been developed in [36]. This work is an extension of the previous studies on beam structures $[37,38]$.

\subsection{The displacement and the strain field}

The displacement solution $\left(u_{1}(x, y, z), u_{2}(x, y, z), u_{3}(x, y, z)\right)$ is constructed as the sum of $N$ products of functions of in-plane coordinates and transverse coordinate $(N \in \mathbb{N}$ is the order of the representation)

$[u]=\left[\begin{array}{l}u_{1}(x, y, z) \\ u_{2}(x, y, z) \\ u_{3}(x, y, z)\end{array}\right]=\sum_{i=1}^{N}\left[\begin{array}{l}f_{1}^{i}(z) v_{1}^{i}(x, y) \\ f_{2}^{i}(z) v_{2}^{i}(x, y) \\ f_{3}^{i}(z) v_{3}^{i}(x, y)\end{array}\right]=\sum_{i=1}^{N}\left[\begin{array}{l}f_{1}^{i}(z) \\ f_{2}^{i}(z) \\ f_{3}^{i}(z)\end{array}\right] \circ\left[\begin{array}{c}v_{1}^{i}(x, y) \\ v_{2}^{i}(x, y) \\ v_{3}^{i}(x, y)\end{array}\right]$

where $\left(f_{1}^{i}, f_{2}^{i}, f_{3}^{i}\right)$ are defined in $\Omega_{z}$ and $\left(v_{1}^{i}, v_{2}^{i}, v_{3}^{i}\right)$ are defined in $\Omega$. The "o" operator is Hadamard's element-wise product.

In this paper, a classical eight-node FE approximation is used in $\Omega$ and a LW description is chosen in $\Omega_{z}$ as it is particulary suitable for the modeling of composite structure. The strain derived from Eq. (3) is 


$$
[\varepsilon(u)]=\sum_{i=1}^{N}\left[\begin{array}{c}
f_{1}^{i} v_{1,1}^{i} \\
f_{2}^{i} v_{2,2}^{i} \\
\left(f_{3}^{i}\right)^{\prime} v_{3}^{i} \\
\left(f_{2}^{i}\right)^{\prime} v_{2}^{i}+f_{3}^{i} v_{3,2}^{i} \\
\left(f_{1}^{i}\right)^{\prime} v_{1}^{i}+f_{3}^{i} v_{3,1}^{i} \\
f_{1}^{i} v_{1,2}^{i}+f_{2}^{i} v_{2,1}^{i}
\end{array}\right]
$$

where the prime stands for the classical derivative $\left(f_{i}^{\prime}=\frac{d f_{i}}{d z}\right)$, and ()$_{, \alpha}$ for the partial derivative.

\subsection{The problem to be solved}

For sake of clarity, the surfaces forces are neglected in the developments and the weak form of the plate problem introduced in Eq. (2) simplifies in

$\int_{\Omega} \int_{\Omega_{z}}\left([\varepsilon(\delta \vec{u})]^{T}[C][\varepsilon(\vec{u})]+[\delta u]^{T}[b]\right) d z d \Omega=0$

where $[C]$ represents, in each layer $(k)$, the matrix of the elastic moduli.

Eq. (5) is solved by an iterative procedure. If we assume that the first $n$ functions have been already computed, the trial function for the iteration $n+1$ is written as

$\left[u^{n+1}\right]=\left[u^{n}\right]+\left[\begin{array}{l}f_{1} v_{1} \\ f_{2} \\ f_{3} \\ v_{3}\end{array}\right]=\left[u^{n}\right]+[f] \circ[v]$

where $\left(v_{1}, v_{2}, v_{3}\right),\left(f_{1}, f_{2}, f_{3}\right)$ are the functions to be computed and $\left[u^{n}\right]$ is the associated known set at iteration $n$ defined by

$\left[u^{n}\right]=\sum_{i=1}^{n}\left[\begin{array}{ll}f_{1}^{i} & v_{1}^{i} \\ f_{2}^{i} & v_{2}^{i} \\ f_{3}^{i} & v_{3}^{i}\end{array}\right]$

The test function is

$\delta\left[\begin{array}{ll}f_{1} & v_{1} \\ f_{2} & v_{2} \\ f_{3} & v_{3}\end{array}\right]=\left[\begin{array}{l}\delta f_{1} v_{1}+f_{1} \delta v_{1} \\ \delta f_{2} v_{2}+f_{2} \delta v_{2} \\ \delta f_{3} v_{3}+f_{3} \delta v_{3}\end{array}\right]=[\delta f] \circ[v]+[\delta v] \circ[f]$

with

$[v]=\left[\begin{array}{l}v_{1} \\ v_{2} \\ v_{3}\end{array}\right] \quad[f]=\left[\begin{array}{l}f_{1} \\ f_{2} \\ f_{3}\end{array}\right]$

The test function defined by Eq. (8) and the trial function defined by Eq. (6) are introduced into the weak form Eq. (5) to obtain the two following equations:

$$
\begin{aligned}
& \int_{\Omega} \int_{\Omega_{z}}\left([\varepsilon(f \circ \delta v)]^{T}[C][\varepsilon(f \circ v)]\right) d z d \Omega \\
& \quad=\int_{\Omega} \int_{\Omega_{z}}\left([f \circ \delta v]^{T}[b]-[\varepsilon(f \circ \delta v)]^{T}[C]\left[\varepsilon\left(u^{n}\right)\right]\right) d z d \Omega
\end{aligned}
$$

$$
\begin{aligned}
& \int_{\Omega_{z}} \int_{\Omega}\left([\varepsilon(v \circ \delta f)]^{T}[C][\varepsilon(v \circ f)]\right) d \Omega d z \\
& \quad=\int_{\Omega_{z}} \int_{\Omega}\left(-[\varepsilon(v \circ \delta f)]^{T}[C]\left[\varepsilon\left(u^{n}\right)\right]+[v \circ \delta f]^{T}[b]\right) d \Omega d z
\end{aligned}
$$

As these equations define a coupled non linear problem, a non linear resolution strategy has to be used. The simplest strategy is a fixed point method. An initial function $f^{(0)}$ is set, and at each step, the algorithm computes a new pair $\left(v^{(m+1)}, f^{(m+1)}\right)$ such that
- $v^{(m+1)}$ satisfies Eq. (10) for $f$ set to $f^{(m)}$ (i.e. $F$ is given),

- $f^{(m+1)}$ satisfies Eq. (11) for $v$ set to $v^{(m+1)}$ (i.e. $V$ is given).

These two equations are linear and the first one is solved on $\Omega$, while the second one is solved on $\Omega_{z}$. The fixed point algorithm is stopped when

$\frac{\left\|v^{(m+1)} \circ f^{(m+1)}-v^{(m)} \circ f^{(m)}\right\|_{\mathcal{V}}}{\left\|v^{(0)} \circ f^{(0)}\right\|_{\mathcal{V}}} \leqslant \varepsilon$

where $\|A\|_{\mathcal{V}}=\left[\int_{\Omega} \int_{\Omega_{z}} \sum_{i=1}^{3} A_{i}^{2} d x d y d z\right]^{1 / 2}$ and $\varepsilon$ is a small parameter to be fixed by the user.

\subsection{Finite element discretization}

To build the plate finite element approximation, a discrete representation of the functions $(v, f)$ must be introduced. We use a classical finite element approximation in $\Omega$, and a polynomial expansion in $\Omega_{\mathrm{z}}$. The elementary vector of degrees of freedom (dof) associated with one element $\Omega_{e}$ of the mesh in $\Omega$ is denoted $\left[q_{e}^{v}\right]$. The vector of dofs associated with the polynomial expansion in $\Omega_{z}$ is denoted $\left[q^{f}\right]$. The displacement fields and the strain fields are determined from the values of $\left[q_{e}^{v}\right]$ and $\left[q^{f}\right]$ by

$\left[v_{e}\right]=\left[N_{x y}\right]\left[q_{e}^{v}\right], \quad\left[\mathcal{E}_{v}^{e}\right]=\left[B_{x y}\right]\left[q_{e}^{v}\right], \quad[f]=\left[N_{z}\right]\left[q^{f}\right]$ and $\left[\mathcal{E}_{f}\right]=\left[B_{z}\right]\left[q^{f}\right]$

where

$\left[\mathcal{E}_{v}^{e}\right]^{T}=\left[\begin{array}{lllllllll}v_{1} & v_{1,1} & v_{1,2} & v_{2} & v_{2,1} & v_{2,2} & v_{3} & v_{3,1} & v_{3,2}\end{array}\right]$

and

$\left[\mathcal{E}_{f}\right]^{T}=\left[\begin{array}{llllll}f_{1} & f_{1}^{\prime} & f_{2} & f_{2}^{\prime} & f_{3} & f_{3}^{\prime}\end{array}\right]$

The matrices $\left[N_{x y}\right],\left[B_{x y}\right],\left[N_{z}\right],\left[B_{z}\right]$ contain the interpolation functions, their derivatives and the jacobian components.

\subsection{Finite element problem to be solved on $\Omega$}

For the sake of simplicity, the function $f^{(m)}$ which is assumed to be known, will be denoted $\tilde{f}$, and the function $v^{(m+1)}$ to be computed will be denoted $v$. The strain in Eq. (10) is defined in matrix notations as

$[\varepsilon(\tilde{f} \circ v)]=\left[\Sigma_{z}(\tilde{f})\right]\left[\mathcal{E}_{v}\right]$

with

$\left[\Sigma_{z}(\tilde{f})\right]=\left[\begin{array}{ccccccccc}0 & \tilde{f}_{1} & 0 & 0 & 0 & 0 & 0 & 0 & 0 \\ 0 & 0 & 0 & 0 & 0 & \tilde{f}_{2} & 0 & 0 & 0 \\ 0 & 0 & 0 & 0 & 0 & 0 & \tilde{f}_{3}^{\prime} & 0 & 0 \\ 0 & 0 & 0 & \tilde{f}_{2}^{\prime} & 0 & 0 & 0 & 0 & \tilde{f}_{3} \\ \tilde{f}_{1}^{\prime} & 0 & 0 & 0 & 0 & 0 & 0 & \tilde{f}_{3} & 0 \\ 0 & 0 & \tilde{f}_{1} & 0 & \tilde{f}_{2} & 0 & 0 & 0 & 0\end{array}\right]$

The variational problem defined on $\Omega$ from Eq. (10) is

$$
\begin{aligned}
\int_{\Omega}\left[\delta \mathcal{E}_{v}\right]^{T}\left[k_{z}(\tilde{f})\right]\left[\mathcal{E}_{v}\right] d \Omega= & \int_{\Omega}[\delta v]^{T}\left[b_{z}(\tilde{f})\right] d \Omega \\
& -\int_{\Omega}\left[\delta \mathcal{E}_{v}\right]^{T}\left[\sigma_{z}\left(\tilde{f}, u^{n}\right)\right] d \Omega
\end{aligned}
$$

with 


$$
\begin{aligned}
& {\left[k_{z}(\tilde{f})\right]=\int_{\Omega_{z}}\left[\Sigma_{z}(\tilde{f})\right]^{T}[C]\left[\Sigma_{z}(\tilde{f})\right] d z} \\
& {\left[b_{z}(\tilde{f})\right]=\int_{\Omega_{z}}[\tilde{f}] \circ[b] d z} \\
& {\left[\sigma_{z}\left(\tilde{f}, u^{n}\right)\right]=\int_{\Omega_{z}}\left[\Sigma_{z}(\tilde{f})\right]^{T}[C]\left[\varepsilon\left(u^{n}\right)\right] d z}
\end{aligned}
$$

The introduction of the finite element approximation Eq. (13) in the variational equation (16) leads to the linear system

$\left[K_{z}(\tilde{f})\right]\left[q^{v}\right]=\left[\mathcal{R}_{v}\left(\tilde{f}, u^{n}\right)\right]$

where

- $\left[q^{v}\right]$ is the vector of the nodal displacements associated with the finite element mesh in $\Omega$,

- $\left[K_{z}(\tilde{f})\right]$ is the stiffness matrix obtained by summing the elements' stiffness matrices $\left[K_{z}^{e}(\tilde{f})\right]=\int_{\Omega_{e}}\left[B_{x y}\right]^{T}\left[k_{z}(\tilde{f})\right]\left[B_{x y}\right] d \Omega_{e}$,

- $\left[\mathcal{R}_{v}\left(\tilde{f}, u^{n}\right)\right]$ is the equilibrium residual obtained by summing the elements' residual load vectors $\left[\mathcal{R}_{v}^{e}\left(\tilde{f}, u^{n}\right)\right]=\int_{\Omega_{e}}\left[N_{x y}\right]^{T}\left[b_{z}(\tilde{f})\right] d x-$ $\int_{\Omega_{e}}\left[B_{x y}\right]^{T}\left[\sigma_{z}\left(\tilde{f}, u^{n}\right)\right] d \Omega_{e}$.

\subsection{Finite element problem to be solved on $\Omega_{z}$}

For the sake of simplicity, the function $v^{(m+1)}$ which is assumed to be known, will be denoted $\tilde{v}$, and the function $f^{(m+1)}$ to be computed will be denoted $f$. The strain in Eq. (11) is defined in matrix notations as

$[\varepsilon(\tilde{v} \circ f)]=\left[\Sigma_{x y}(\tilde{v})\right]\left[\mathcal{E}_{f}\right]$

with

$$
\left[\Sigma_{x y}(\tilde{\nu})\right]=\left[\begin{array}{cccccc}
\tilde{v}_{1,1} & 0 & 0 & 0 & 0 & 0 \\
0 & 0 & \tilde{v}_{2,2} & 0 & 0 & 0 \\
0 & 0 & 0 & 0 & 0 & \tilde{v}_{3} \\
0 & 0 & 0 & \tilde{v}_{2} & \tilde{v}_{3,2} & 0 \\
0 & \tilde{v}_{1} & 0 & 0 & \tilde{v}_{3,1} & 0 \\
\tilde{v}_{1,2} & 0 & \tilde{v}_{2,1} & 0 & 0 & 0
\end{array}\right]
$$

The variational problem defined on $\Omega_{z}$ from Eq. (11) is

$$
\begin{aligned}
\int_{\Omega_{z}}\left[\delta \mathcal{E}_{f}\right]^{T}\left[k_{x y}(\tilde{v})\right]\left[\mathcal{E}_{f}\right] d z= & \int_{\Omega_{z}}[\delta f]^{T}\left[b_{x y}(\tilde{\mathcal{v}})\right] d z \\
& -\int_{\Omega_{z}}\left[\delta \mathcal{E}_{f}\right]^{T}\left[\sigma_{x y}\left(\tilde{\mathcal{v}}, u^{n}\right)\right] d z
\end{aligned}
$$

with

$$
\begin{aligned}
& {\left[k_{x y}(\tilde{\mathcal{v}})\right]=\int_{\Omega}\left[\Sigma_{x y}(\tilde{\mathcal{v}})\right]^{T}[C]\left[\Sigma_{x y}(\tilde{\mathcal{v}})\right] d \Omega} \\
& {\left[b_{x y}(\tilde{\mathcal{v}})\right]=\int_{\Omega}[\tilde{\mathcal{v}}] \circ[b] d \Omega} \\
& {\left[\sigma_{x y}\left(\tilde{\mathcal{v}}, u^{n}\right)\right]=\int_{\Omega}\left[\Sigma_{x y}(\tilde{v})\right]^{T}[C]\left[\varepsilon\left(u^{n}\right)\right] d \Omega}
\end{aligned}
$$

The introduction of the finite element discretization Eq. (13) in the variational equation (23) leads to the linear system

$$
\left[K_{x y}(\tilde{v})\right]\left[q^{f}\right]=\left[\mathcal{R}_{f}\left(\tilde{v}, u^{n}\right)\right]
$$

where $\left[q^{f}\right]$ is the vector of degree of freedom associated with the polynomial expansion in $\Omega_{z},\left[K_{x y}(\tilde{v})\right]$ is a stiffness matrix defined by Eq. (28) and $\left[\mathcal{R}_{f}\left(\tilde{\nu}, u^{n}\right)\right]$ an equilibrium residual defined by Eq. (29)

$\left[K_{x y}(\tilde{\mathcal{v}})\right]=\int_{\Omega_{z}}\left[B_{z}\right]^{T}\left[k_{x y}(\tilde{\mathcal{v}})\right]\left[B_{z}\right] d z$
$\left[\mathcal{R}_{f}\left(\tilde{v}, u^{n}\right)\right]=\int_{\Omega_{z}}\left[N_{z}\right]^{T}\left[b_{x y}(\tilde{v})\right] d z-\int_{\Omega_{z}}\left[B_{z}\right]^{T}\left[\sigma_{x y}\left(\tilde{v}, u^{n}\right)\right] d z$

Remark: To impose the subscribed displacements on a region of the structure, the first couple is chosen such that it ensures this requirement. Then, the following couples are built by satisfying a nil condition in this region.

\section{Numerical results}

In this section, static tests are presented for assessing our approach and evaluating its capacity to capture steep variation of stresses. Note that the properties of the FE are not studied in the present work.

Furthermore, comparisons with results available in open literature are also provided, they are described below:

LD4 It refers to the systematic work of Carrera and his "Carrera's Unified Formulation" (CUF), see [39,20,40]. A LayerWise model based on a displacement approach where each component is expanded until the fourth order is given; $12 N C+3$ unknown functions are used in this kinematic.

Wang and Crossman (1977) They employed three-node triangular elements for discretizing the $(x, y)$-plane of the laminate with a generalized plane strain assumption [29].

Tahani and Nosier (2003) The semi-analytical solution approach [41] solves in closed-form the boundary layer in the direction perpendicular to the stress-free edge (the $y$ direction), while an approximate solution is found along the throughthickness direction (the $z$ direction). The latter is defined according to Reddy's layer-wise theory upon discretizing the thickness of each ply in several mathematical layers, in which the field variables are interpolated through linear Lagrange polynomials. In this approach, the stress-free conditions at the free edge are thus enforced in an averaged sense by means of weighted integrals. The results are obtained with 15 subdivisions per ply.

Spilker and Chou (1980) The mixed HR principle is employed for developing hybrid-stress FE. Their generalized plane strain quadrilateral has through-thickness cubic and quadratic approximations for the in-plane and transverse displacement, respectively. Independent approximations are introduced for the stress field: $\sigma_{y y}, \sigma_{z z}$ and $\sigma_{y z}$ vary across the thickness of each element with $z^{3}, z^{5}$ and $z^{4}$, respectively.

Mittelstedt and Becker (2007) A quasi-analytical approach based on a first-order LW description of the kinematics is used. Robbins and Reddy (1993) A LayerWise kinematics in which the displacement components are interpolated along $z$ through Lagrange polynomials is used in conjunction with eight-node quadratic plate elements in the $(x, y)$-plane. 4 mathematical layers and a quadratic polynomial expansion for each layer are considered.

\subsection{Description of the problem}

The free-edge effects are investigated by referring to the Pipes-Pagano problem illustrated in Fig. 1. According to the common definition of this classical benchmark, the plate width is taken to be $2 b$, the total thickness made of $N C$ identical plies is $2 h=N C h_{k}$ and the ratio $b=4 h$ is employed [24,29,41,31]. A uniform axial strain $\epsilon_{0}$ is applied along the $x$-axis by prescribing end displacements $\bar{u}$ at $x= \pm a$. All results will be reported in nondimensional form. The uniform traction load induces a constant strain state along the $x$-axis in the central region of the plate. Convergence studies performed with 3D Ansys elements, not presented for the sake of conciseness, have shown that $a=2 b=8 h$ provides 
Table 1

Material properties of the ply (all moduli in $\mathrm{MPa}$ ).

$$
\begin{aligned}
& E_{1}=137900, E_{2}=E_{3}=14480 \\
& G_{12}=G_{13}=G_{23}=5860 \\
& v_{12}=v_{13}=v_{23}=0.21
\end{aligned}
$$

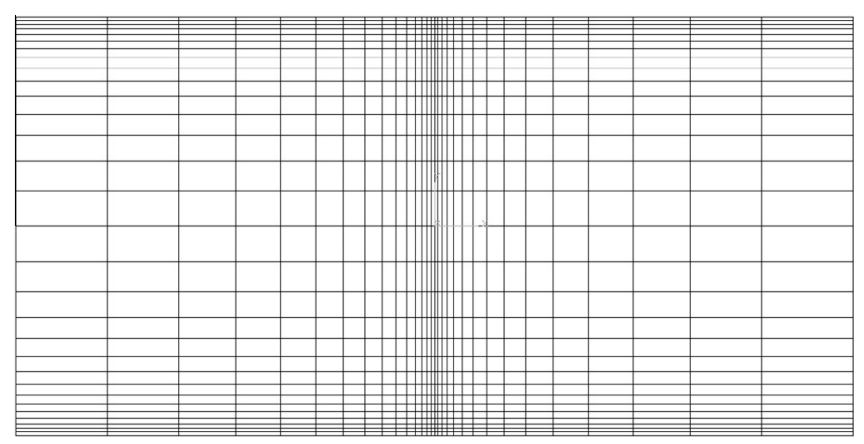

Fig. 2. Mesh employed in the $x y$-plane for the 3D and plate simulations.

a sufficient plate length. All plies are CFRP composites with the material properties given in Table 1 . These material properties correspond to those employed in previous reference works $[24,29,32,41]$ allowing a direct comparison of the results.
In the following, the free-edge effects are studied which arise in classical symmetric laminates, namely the cross-ply laminate $\left[90^{\circ}, 0^{\circ}\right]_{S}$, the angle-ply laminate $\left[ \pm 45^{\circ}\right]_{S}$ and the quasi-isotropic laminate $\left[45^{\circ},-45^{\circ}, 0^{\circ}, 90^{\circ}\right]_{s}$, see $[29,42]$.

A mesh with decreasing element size towards the free edge $y=b$ is employed in order to capture the steep gradients of the response. 3D FEM computations with ANsYs are performed for providing a reference with solid elements. Appropriate spacing ratios are defined for the 3D mesh which ensure a perfectly cubic shape of the smallest element at the free edge. Several analyses conducted with a different number of elements, not shown for the sake of conciseness, have shown that a mesh with $32 \times 32$ elements in the $x y$-plane is enough to capture local effects, see Fig. 2. The same mesh is considered in the $x y$-plane for the PGD computations. This convergence study is not addressed in the present work as a singularity behavior occurs in the vicinity of the free edge. Nevertheless, dedicated mesh refinement strategies exist to measure this one as in [43].

\subsection{Cross-ply laminate $\left[90^{\circ}, 0^{\circ}\right]_{S}$}

\subsubsection{Illustration of the behavior of the approach}

First, the behavior of the approach is studied and discussed. Ten couples $\left(v^{i}, f^{i}\right)$ are needed to obtain the converged solution for the cross-ply laminate. For illustration, they are reported in Figs. 3-8 for both the $z$-function and in-plane functions of the displacements $u_{2}$ and $u_{3}$ respectively. For each couple, the $z$-functions are
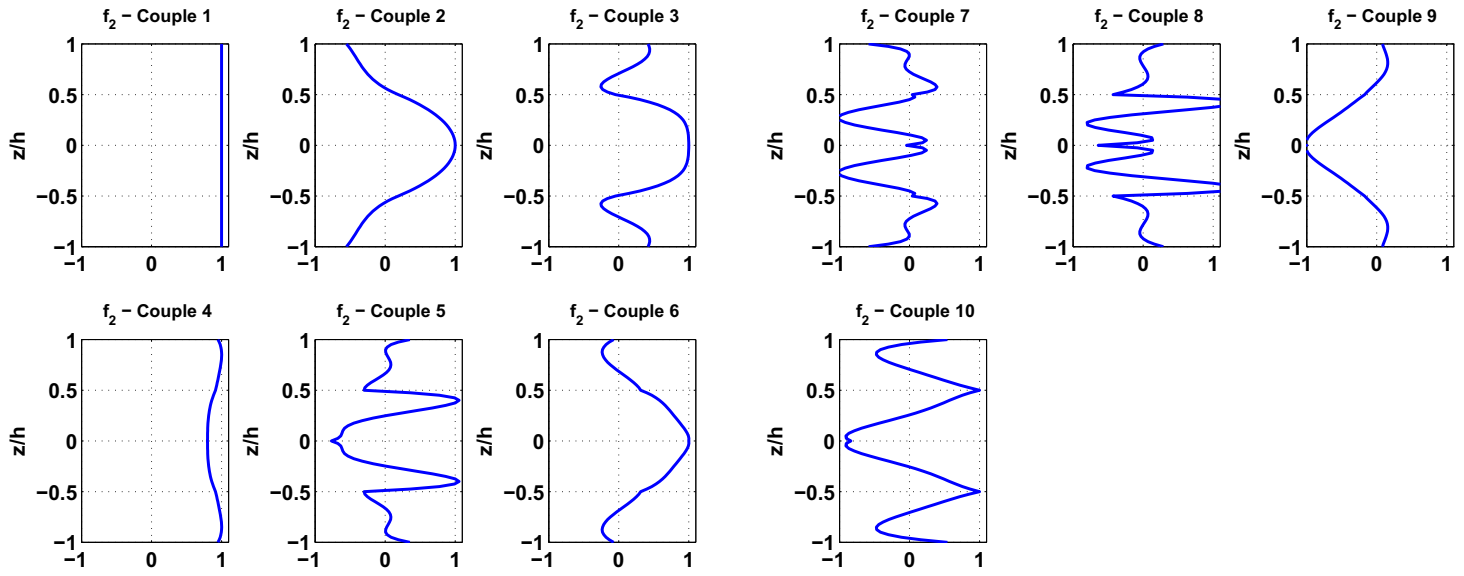

Fig. 3. 10 Couples $f_{2}(z)-\left[90^{\circ}, 0^{\circ}\right]_{S}$.
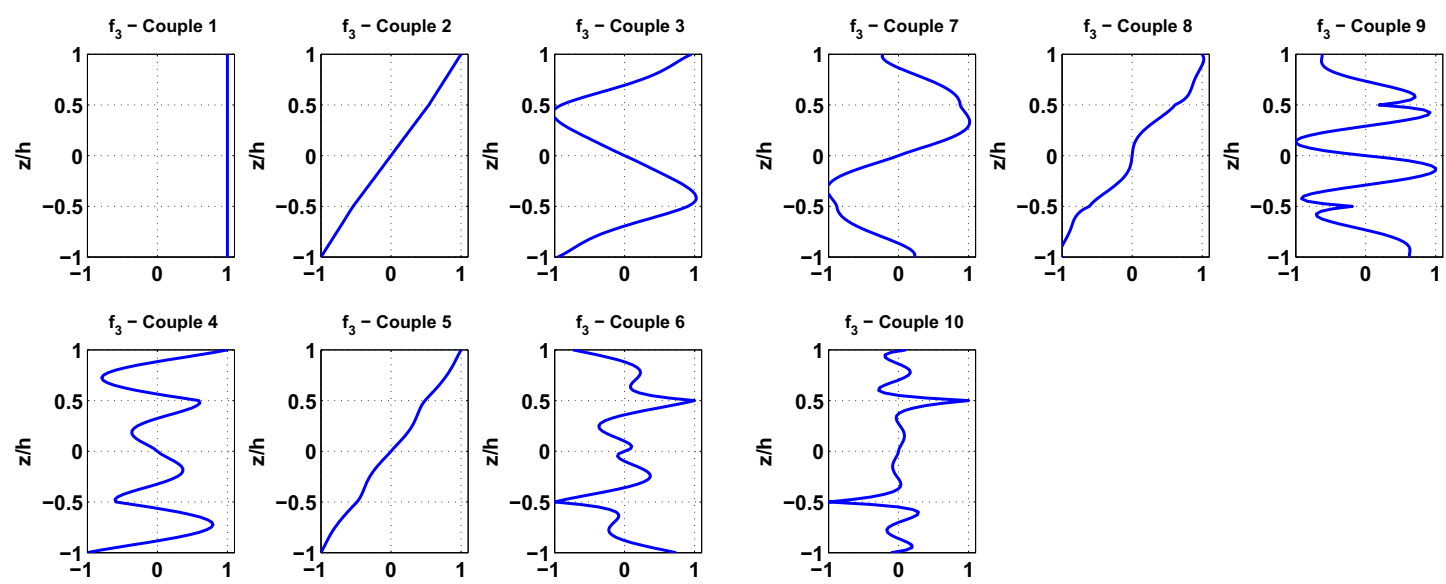

Fig. 4. 10 Couples $f_{3}(z)-\left[90^{\circ}, 0^{\circ}\right]_{s}$. 

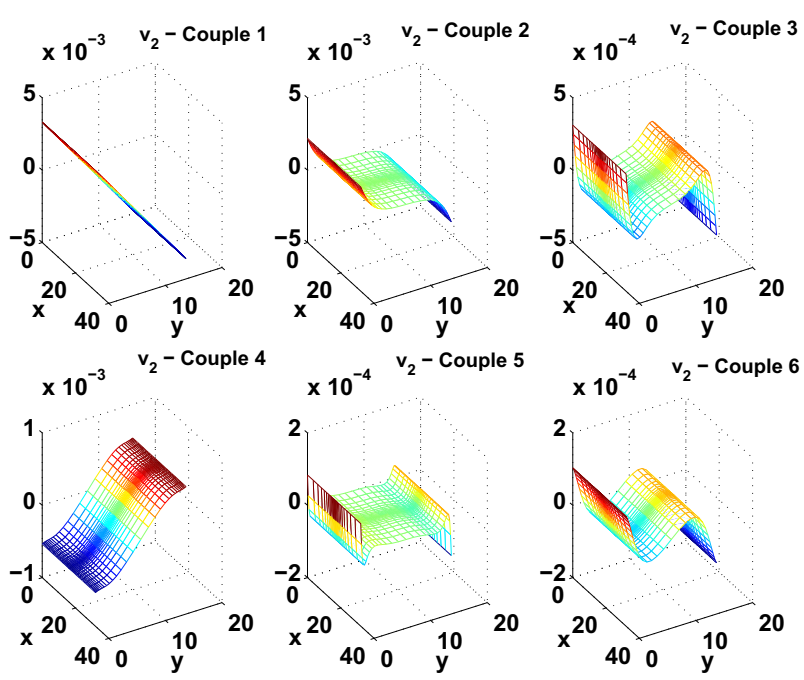

Fig. 5. Couples $1-6-v_{2}(x, y)-\left[90^{\circ}, 0^{\circ}\right]_{s}$.
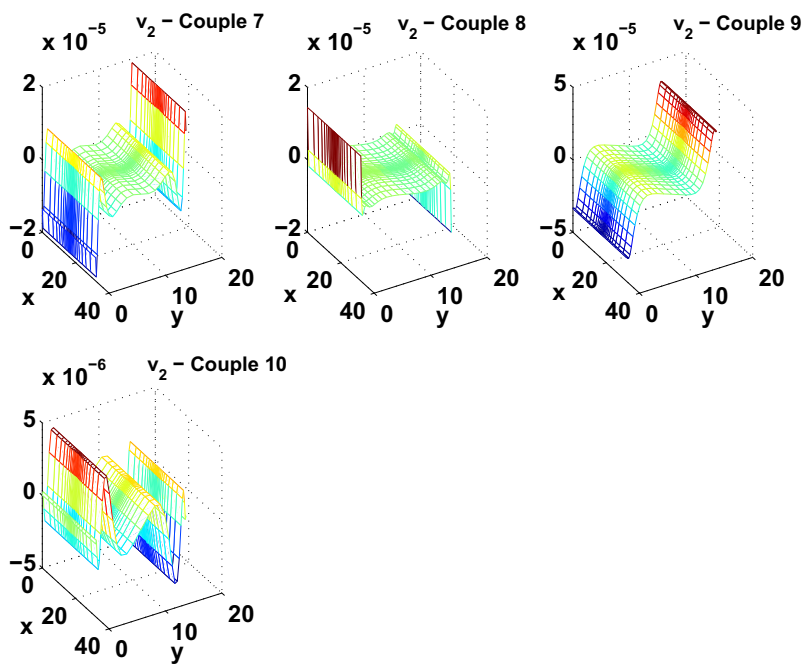

Fig. 6. Couples $7-10-v_{2}(x, y)-\left[90^{\circ}, 0^{\circ}\right]_{s}$.
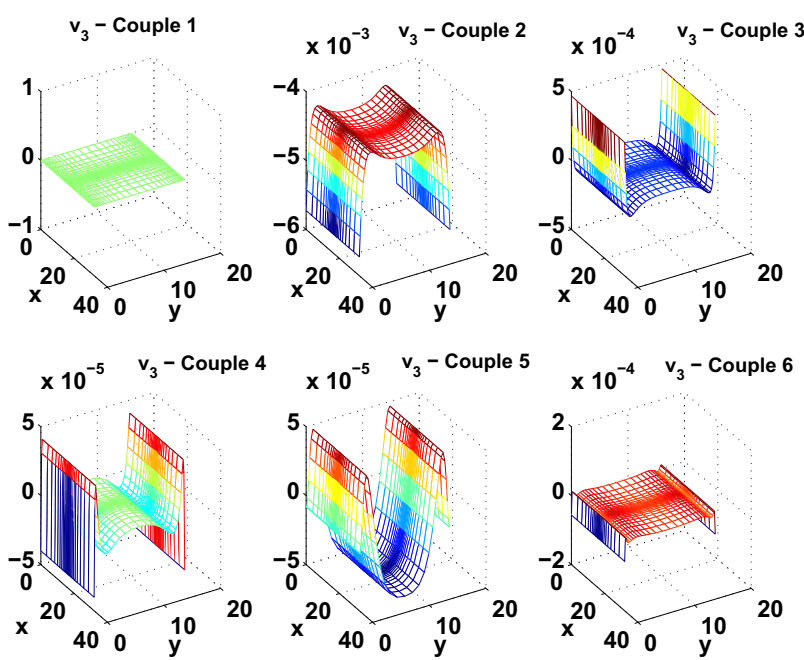

Fig. 7. Couples $1-6-v_{3}(x, y)-\left[90^{\circ}, 0^{\circ}\right]_{S}$.
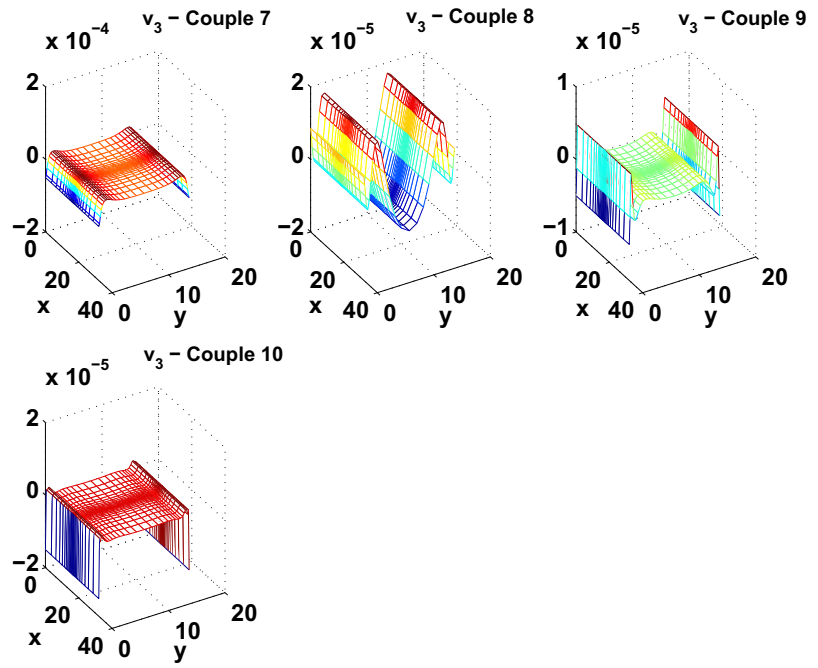

Fig. 8. Couples $7-10-v_{3}(x, y)-\left[90^{\circ}, 0^{\circ}\right]_{s}$.

normalized such as $\max \left(f_{\times}(z)\right)=1$. The functions related to the $z$ coordinate have high and short wavelengths depending on the number of the couple. It emphasizes the importance of the degree of these functions. From Figs. 5, 6 and 7, 8, two types of in-plane functions can be distinguished: global and local modes. These latter are related to the correction of the solution near the free-edge where the steepest gradient of the stresses occurs. Note that the first couple is chosen so as to satisfy the prescribed displacements at $x= \pm a$.

To highlight the capability of the method, the distribution of the strain energy over the plate is given in Fig. 9(a). It can be inferred from this figure that few strain energy is involved near the freeedge which makes the correction of the solution difficult. Moreover, as it can be already observed for other application fields, most of the total strain energy of the solution is included in the first two modes (more than 99\%). The contribution of each couple in the total strain energy is shown in Fig. 9(b). Nevertheless, the contribution of the couple 4 for $v_{2}$ (Fig. 5) is of the same order of magnitude than the first mode. Hence, despite the involved low energy level, the local correction near the free edge could be high.

Finally, low level of energy can be corrected in a very small region without being perturbed by the whole structure, which can make this approach attractive.

\subsubsection{Assessment of the local results}

For further assessment, the present results (denoted PGD LW4thorder) are compared with reference solutions from 3D computations (Ansys) and quasi-3D results from the Carrera's Unified Formulation (LD4) (Figs. 12 (left) and 10). They are also compared with results available in literature (Figs. 12 (right), 11). Their main features are recalled in the introduction of this section. The only non-zero transverse stress components arising in orthotropic laminates subjected to uniaxial straining along $x$ are due to the Poisson mismatch and are the transverse normal stress $\sigma_{z z}$ and the transverse shear stress $\sigma_{y z}$. Figs. 10-12 show their distributions along the $y$-axis at the bi-material interface and through the thickness at the free edge, respectively. In Figs. 10 and 12(left), the results of the present approach agree very well with the 3D and the quasi-3D LD4 solutions, in particular the steep rise of the transverse normal stress is well captured. Comparisons with other LW or plane strain approaches available in literature show also a very good agreement, except for results given by Spilker and Chou [30]. Note that the plane strain approaches are limited to the cross-ply laminates.

So, the capability of the approach to capture localized phenomenon is confirmed for this discriminating test case. 


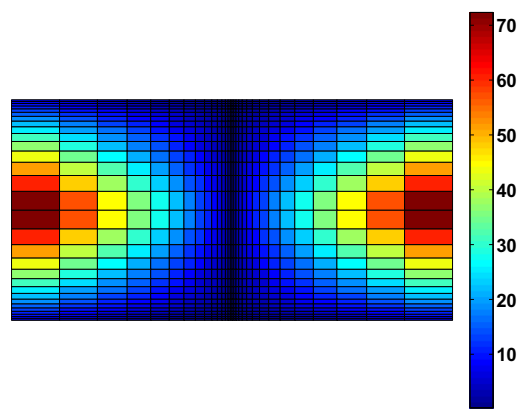

(a) distribution of the strain energy

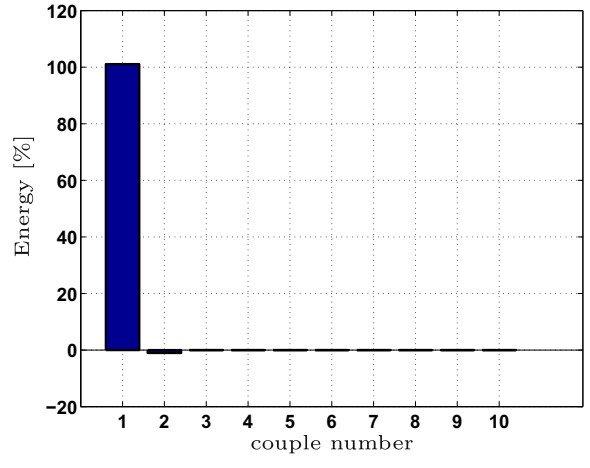

(b) contribution of each couple in the total strain energy [\%]

Fig. 9. $\left[90^{\circ}, 0^{\circ}\right]_{S}$.
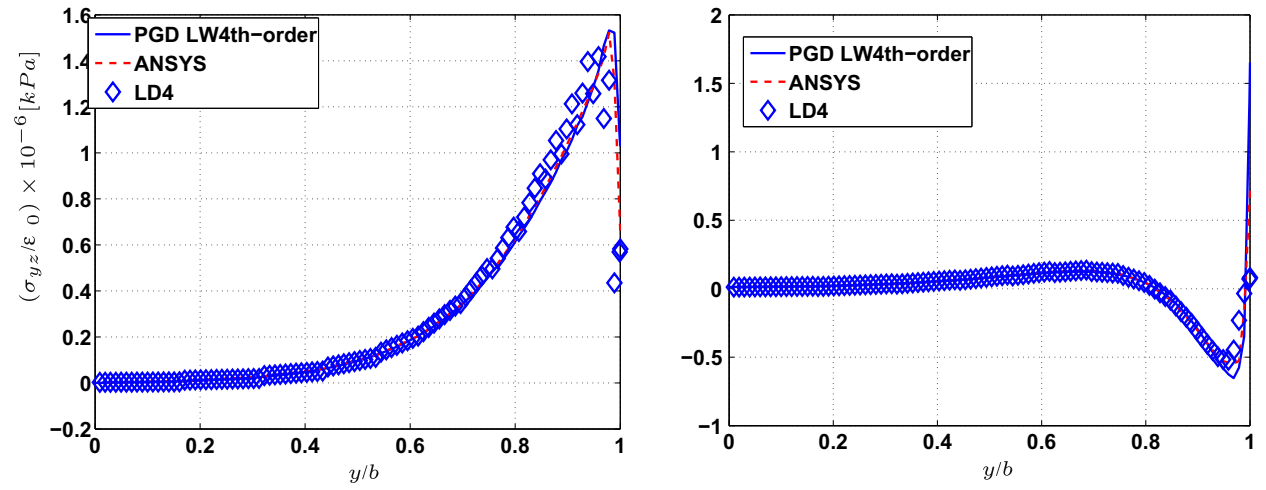

Fig. 10. Distribution of $\sigma_{y z}$ (left) and $\sigma_{z z}$ (right) along $y$ at the bi-material interface $-\left[90^{\circ}, 0^{\circ}\right]_{s}$.
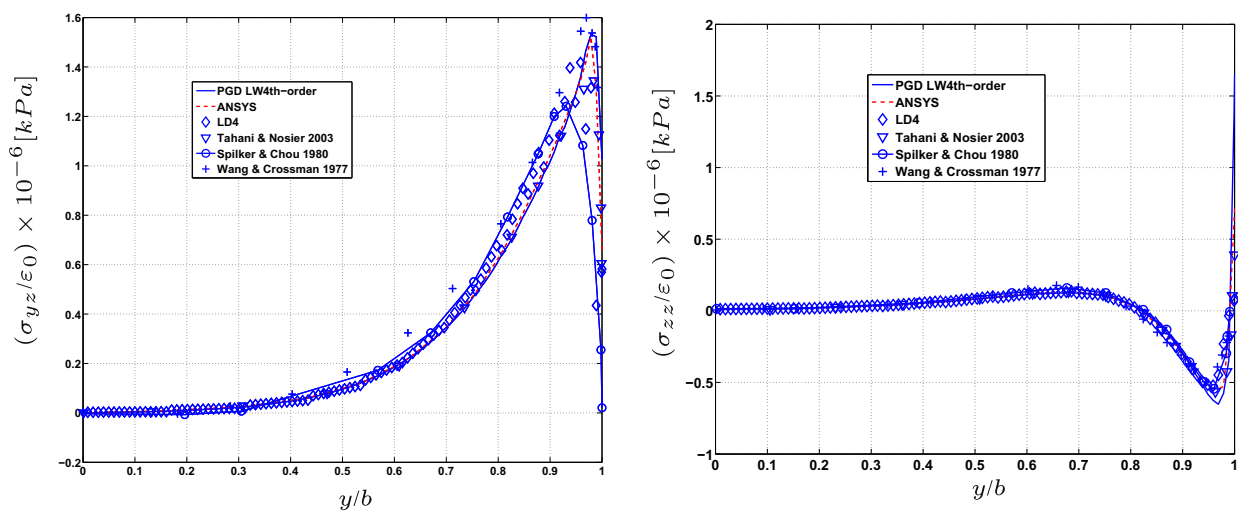

Fig. 11. Distribution of $\sigma_{y z}$ (left) and $\sigma_{z z}$ (right) along $y$ at the bi-material interface $-\left[90^{\circ}, 0^{\circ}\right]_{s}$.

\subsubsection{Influence of the numerical layers}

One of the attractive feature of the method consists of the refinement of the $z$-functions without affecting the computational efficiency (see [36]). Fig. 12 highlights some oscillations of the distribution of $\bar{\sigma}_{z z}(z)$ in the $0^{\circ}$ layer, obtained by the present model. This may be overcome by adding numerical layers, see Fig. 13(right) where 6 numerical layers per physical one are used. This refinement enhances the representation of the stress-free boundary conditions on the top of the plate as well. It should be also noted that the steep gradient of $\bar{\sigma}_{z z}(z)$ is more pronounced near the bi-material interface than those of the $3 \mathrm{D}$ computations, as the refinement becomes more important. Moreover, results for $\bar{\sigma}_{y z}(y)$ and $\bar{\sigma}_{z z}(y)$ are in excellent agreement with the Ansys computations (Cf. Fig. 13 (left-middle)).

\subsection{Angle-ply laminate $\left[45^{\circ},-45^{\circ}\right]_{S}$}

A angle-ply laminate $[ \pm 45]_{S}$ is considered. It has been shown that a high gradient at the bi-material interface occurs (see [28]) which makes this test case a very challenging one for $2 \mathrm{D}$ plate models. In this case, twelve couples are built. First, the distribution of the transverse shear and normal stresses through the thickness at $y=0.999 \mathrm{~b}$ is presented in Fig. 14. The high gradient at the bimaterial interfaces is rather well captured by the present approach 

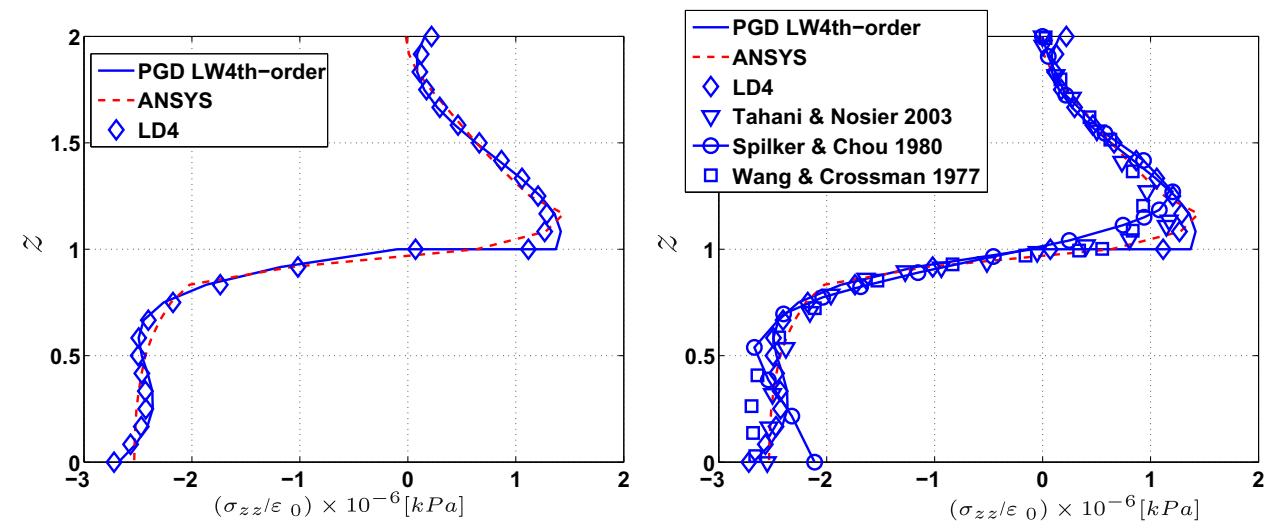

Fig. 12. Distribution of $\sigma_{z z}$ (right) along the thickness $-y=0.999 \mathrm{~b}-\left[90^{\circ}, 0^{\circ}\right]_{s}$.
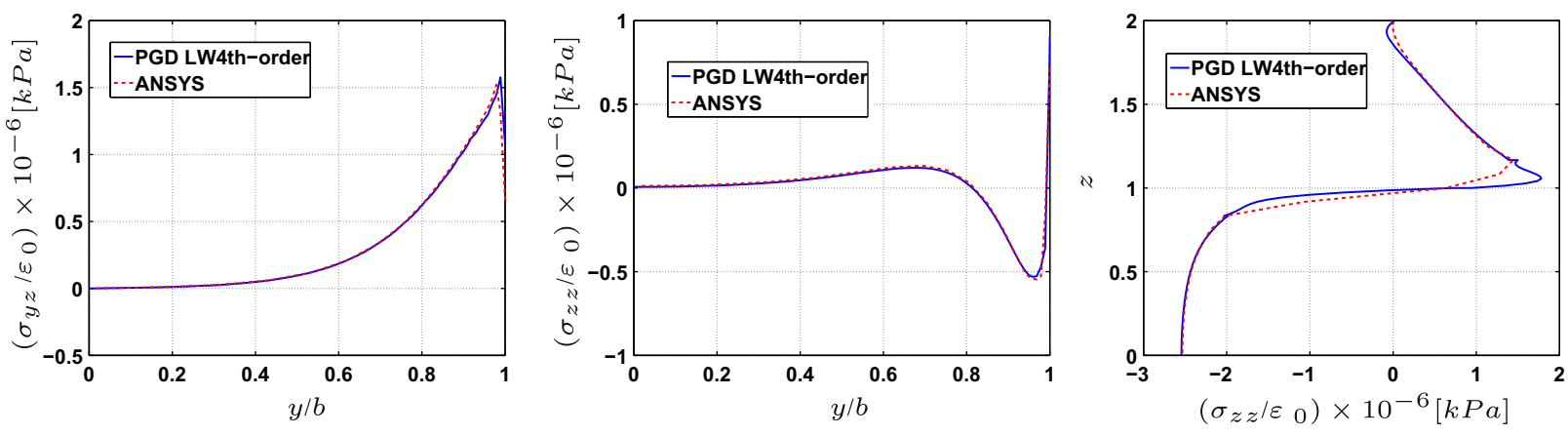

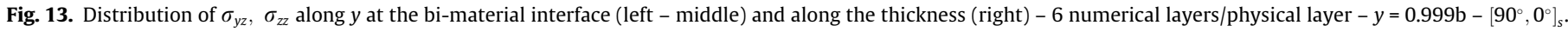
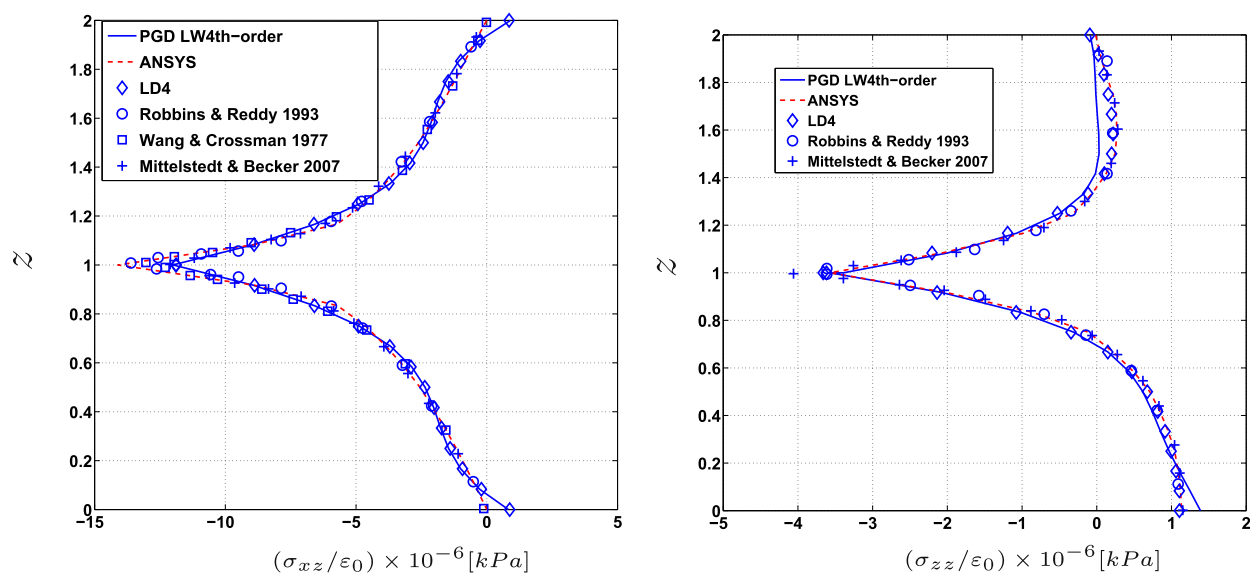

Fig. 14. Distribution of $\sigma_{x z}$ (left) and $\sigma_{z z}$ (right) along the thickness $-y=0.999 \mathrm{~b}-\left[ \pm 45^{\circ}\right]_{s}$.

even if the maximum value is under estimated for $\sigma_{x z}$. This can be again overcome by adding numerical layers (See Fig. 15). It seems that a singularity occurs at the interface layers and it is well detected. Note also that the solution is rather close to the reference one and the traction-free boundary condition at the top surface is fulfilled. Moreover, a very good agreement with LW or dedicated approaches available in literature is found. The transverse shear and normal stresses along $y$-axis is also shown in Fig. 16. It is evident that the present approach has the capability to represent the strong variation of the stresses near the free-edge.

For further assessment, the number of dofs involved in the present method and in the 3D FEM computation is given in Table 2. It allows us to give an illustration about the computational cost, even if the present method requires several resolutions. For this test, a ratio of about 22 is obtained. Moreover, the refinement of the transverse functions with numerical layers increases only the number of unknowns of the 1D problem. This does not affect the total computational cost. It is not the case for the 3D problem where additional elements per physical layer must be added.

\subsection{Quasi isotropic laminate $\left[45^{\circ},-45^{\circ}, 0^{\circ}, 90^{\circ}\right]_{S}$}

Twelve couples are built for the quasi-isotropic laminate $\left[45^{\circ},-45^{\circ}, 0^{\circ}, 90^{\circ}\right]_{s}$. As for the previous test, a high stress variation along the thickness occurs at the $\pm 45^{\circ}$ interface layer for both the transverse shear and normal stresses, see Fig. 17. Only one numer- 

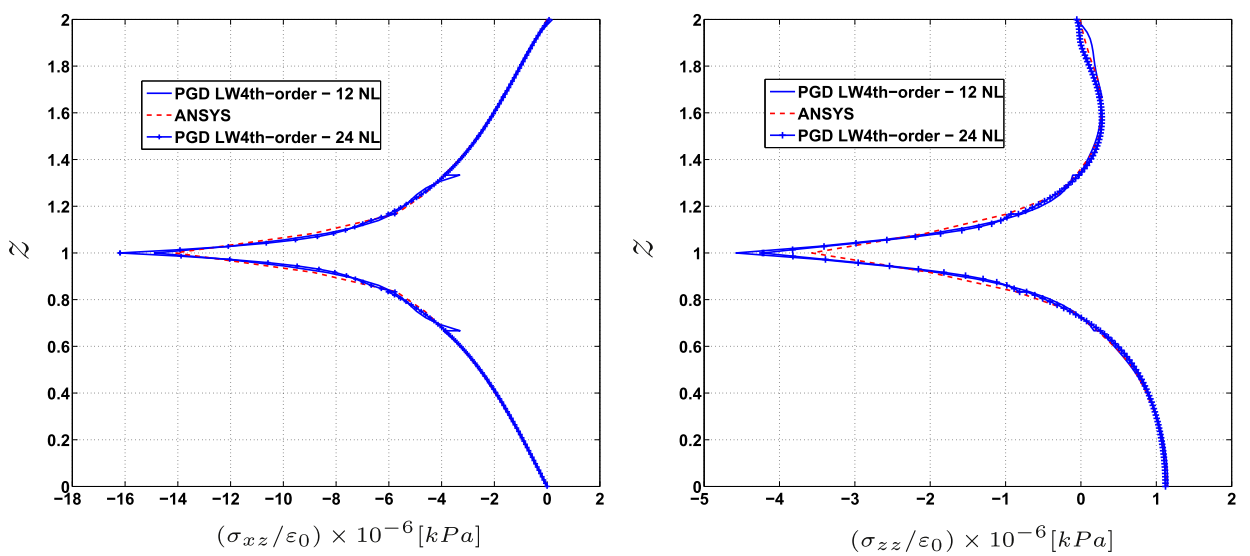

Fig. 15. Distribution of $\sigma_{x z}$ (left) and $\sigma_{z z}$ (right) along the thickness $-y=0.999 \mathrm{~b}-\left[ \pm 45^{\circ}\right]_{s}-12 / 24$ numerical layers (NL).
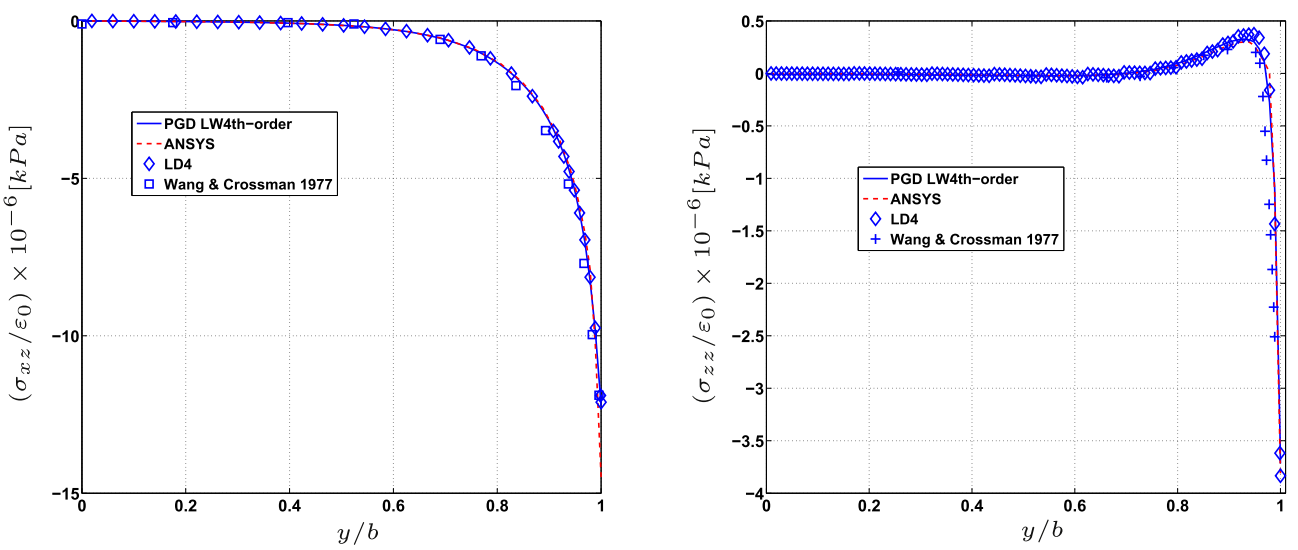

Fig. 16. Distribution of $\sigma_{x z}$ (left) and $\sigma_{z z}$ (right) along $y$ at the bi-material interface $-\left[ \pm 45^{\circ}\right]_{s}$.

Table 2

Number of dofs $-32 \times 32$ elements in the $x y$-plane.

\begin{tabular}{llll}
\hline & $\begin{array}{l}\text { 3D computation } 8 \\
\text { elements per layer }\end{array}$ & Present with 12 NL & Present with 24 NL \\
\hline Number of dofs & 189,999 & $8463(2 \mathrm{D})+291(1 \mathrm{D})$ & $8463(2 \mathrm{D})+579(1 \mathrm{D})$ \\
\hline
\end{tabular}
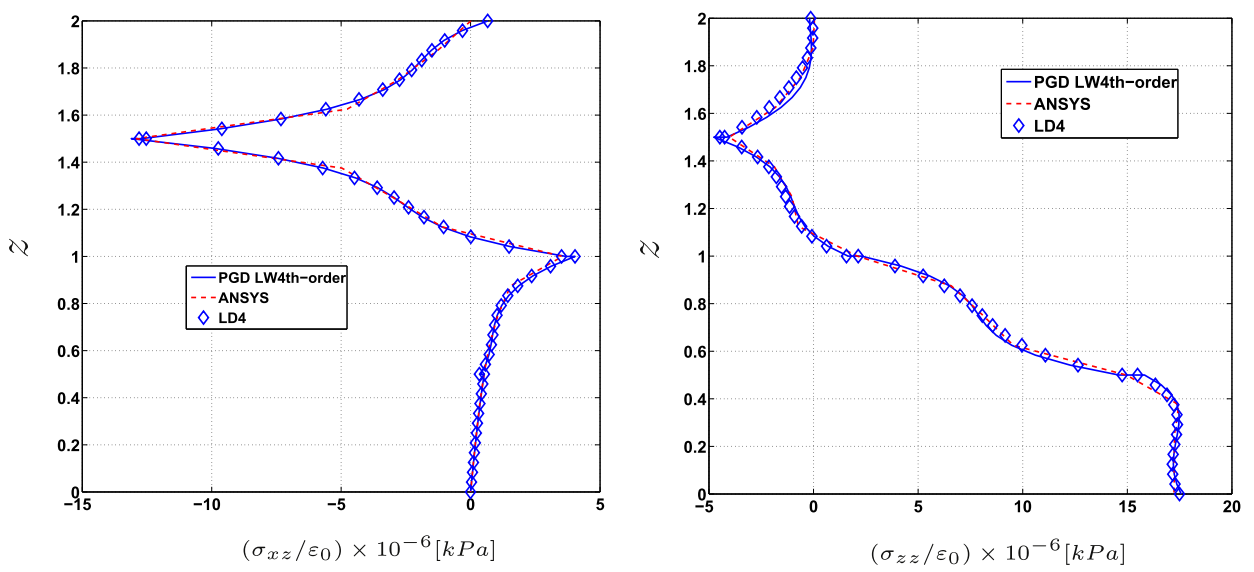

Fig. 17. Distribution of $\sigma_{x z}$ (leftt) and $\sigma_{z z}$ (right) along the thickness $-y=0.999 \mathrm{~b}-\left[45^{\circ},-45^{\circ}, 0^{\circ}, 90^{\circ}\right]_{s}$. 

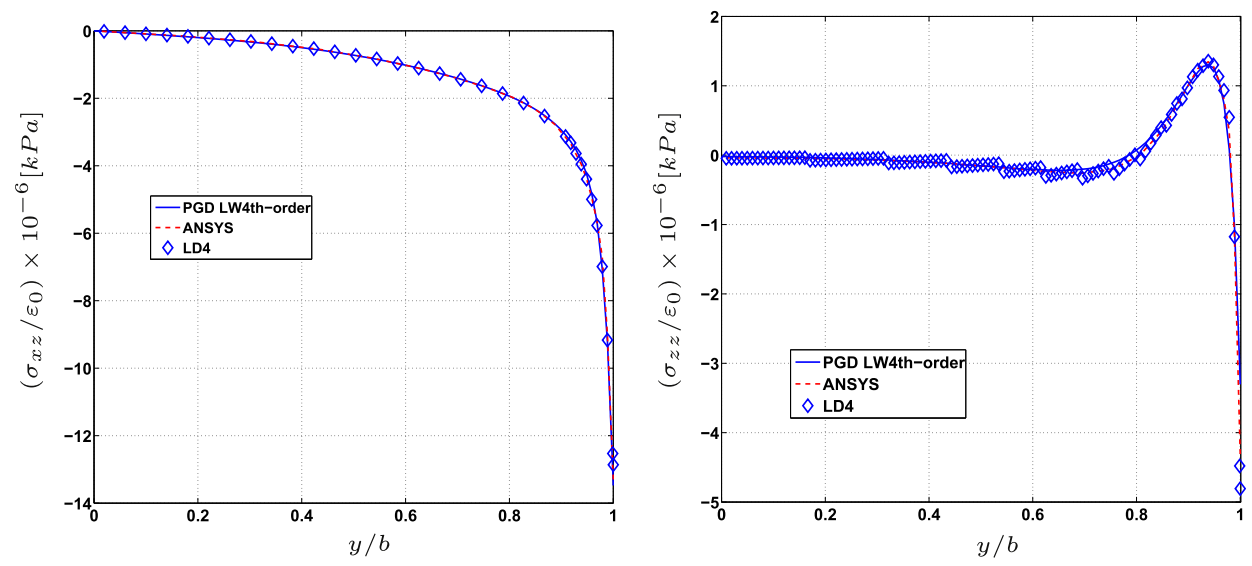

Fig. 18. Distribution of $\sigma_{x z}$ (left) and $\sigma_{z z}$ (right) along $y$ at the bi-material interface $-\left[45^{\circ},-45^{\circ}, 0^{\circ}, 90^{\circ}\right]_{s}$.

ical layer per physical layer is used and the accuracy of the results are very good when compared with the $3 \mathrm{D}$ solution. This is confirmed in Fig. 18 where the variation of $\bar{\sigma}_{13}$ and $\bar{\sigma}_{33}$ along $y$ at the bi-material interface is shown. Hence, high stress gradient in a local region and complex distributions of stresses are obtained by the present approach.

\section{Conclusion}

In this paper, an approach based on the separation of variables for the modeling of the free edge effect in laminated composite plates is assessed. It is based on a 8-node FE for the in-plane displacement approximation and a fourth-order LW description for the thickness displacement approximation. The study is focused on the capability of the present method to capture the steep stress gradients in the vicinity of the stress free edge for different laminates.

The behavior of the approach is first analyzed. It appears that two types of couples can be distinguished: global displacement modes are enhanced by local corrections of the solution. Comparisons with 3D solutions, results available in open literature and high-order models issued from the CUF are performed. They show that this approach can provide accurate 3D stress states in the vicinity of the free edge. Moreover, the number of unknowns remain low when compared with expensive 3D FEM computations. Therefore, this method seems very attractive to capture high stress gradients. Based on these promising results, this low cost numerical tool could be used to evaluate initiation of delamination for straight edge or open hole problems.

\section{References}

[1] Tanigawa Y, Murakami H, Ootao Y. Transient thermal stress analysis of a laminated composite beam. J Therm Stresses 1989;12:25-39.

[2] Yang P, Norris C, Stavsky Y. Elastic wave propagation in heterogeneous plates. Int J Solids Struct 1966;2:665-84.

[3] Lo K, Christensen R, Wu F. A higher-order theory of plate deformation. Part II: Laminated plates. J Appl Mech ASME 1977;44:669-76.

[4] Reddy J. A simple higher-order theory for laminated composite plates. J Appl Mech ASME 1984;51(4):745-52.

[5] Carrera E. A priori vs. a posteriori evaluation of transverse stresses in multilayered orthotropic plates. Compos Struct 2000;48(4):245-60.

[6] Kant T, Swaminathan K. Analytical solutions for the static analysis of laminated composite and sandwich plates based on a higher order refined theory. Compos Struct 2002;56:329-44.

[7] Pagano N. Exact solutions for composite laminates in cylindrical bending. J Comput Mater 1969;3:398-411.

[8] Reddy J. On refined computational models of composite laminates. Int J Numer Methods Eng 1989;27:361-82.

[9] Ferreira A. Analysis of composite plates using a layerwise shear deformation theory and multiquadrics discretization. Mech Adv Mater Struct 2005;12:99-112.
[10] Icardi U. Higher-order zig-zag model for analysis of thick composite beams with inclusion of transverse normal stress and sublaminates approximations. Compos Part B Eng J 2001;32:343-54.

[11] Carrera E. A study of transverse normal stress effect on vibration of multilayered plates and shells. J Sound Vib 1999;225:803-29.

[12] Reddy J. Mechanics of laminated composite plates and shells - theory and analysis. CRC Press Inc.; 2004.

[13] Kapuria S, Dumir P, Ahmed A. An efficient higher order zigzag theory for composite and sandwich beams subjected to thermal loading. Int J Solids Struct 2003:40:6613-31.

[14] Lee C-Y, Liu D, Lu X. Static and vibration analysis of laminated composite beams with an interlaminar shear stress continuity theory. Int J Numer Methods Eng 1992;33:409-24.

[15] Sciuva MD, Icardi U. Numerical assessment of the core deformability effect on the behavior of sandwich beams. Compos Struct 2001;52:41-53.

[16] Vidal P, Polit O. A refined sinus plate finite element for laminated and sandwich structures under mechanical and thermomechanical loads. Comput Methods Appl Mech Eng 2013;253:396-412.

[17] Kapania R, Raciti S. Recent advances in analysis of laminated beams and plates. Part I: shear effects and buckling. AIAA J 1989;27:923-34.

[18] Noor A, Burton W. Assessment of computational models for multilayered composite shells. Appl Mech Rev 1990;43(4):67-97.

[19] Carrera E. Theories and finite elements for multilayered, anisotropic composite plates and shells. Arch Comput Methods Eng 2002;9:87-140.

[20] Carrera E. Historical review of zig-zag theories for multilayered plates and shells. Appl Mech Rev 2003;56(3):287-308.

[21] Reddy J, Arciniega R. Shear deformation plate and shell theories: from Stavsky to present. Mech Adv Mater Struct 2004:11:535-82.

[22] Zhang Y, Yang C. Recent developments in finite elements analysis for laminated composite plates. Compos Struct 2009;88:147-57.

[23] Allix O, Dupleix-Couderc C. A plate theory as a mean to compute precise $3 \mathrm{~d}$ solutions including edge effects and related issues. In: Pimenta P, editor. New trends in thin structures: formulation, optimization and coupled problems. CISM courses and lectures, vol. 519. Vienna: Springer; 2010. p. 1-28.

[24] Pipes RB, Pagano NJ. Interlaminar stresses in composite laminates under uniform axial extension. J Comput Mater 1970;4:538-48.

[25] Pagano NJ, Pipes RB. The influence of stacking sequence on laminate strength. Comput Mater 1971:5:50-7.

[26] Mittelstedt C, Becker W. Interlaminar stress concentrations in layered structures. Part I: A selective literature survey on the free-edge effect since 1967. J Comput Mater 2004;38:1037-62.

[27] Mittelstedt C, Becker W. Free-edge effects in composite laminates. Appl Mech Rev 2007;60:217-45.

[28] D’Ottavio M, Vidal P, Valot E, Polit O. Assessment of plate theories for free-edge effects. Compos Part B Eng J 2013;48:111-21.

[29] Wang ASD, Crossman FW. Some new results on edge effect in symmetric composite laminates. J Comput Mater 1977;11:92-106.

[30] Spilker RL, Chou SC. Edge effects in symmetric composite laminates: importance of satisfying the traction-free-edge condition. J Comput Mater $1980 ; 14: 2-20$

[31] Nguyen V-T, Caron J-F. A new finite element for free edge effect analysis in laminated composites. Comput Struct 2006;84:1538-46.

[32] Robbins D, Reddy J. Modelling of thick composites using a layerwise laminate theory. Int J Numer Methods Eng 1993;36:655-77.

[33] Ammar A, Mokdada B, Chinesta F, Keunings R. A new family of solvers for some classes of multidimensional partial differential equations encountered in kinetic theory modeling of complex fluids. J Non-Newtonian Fluid Mech 2006;139:153-76.

[34] Savoia M, Reddy J. A variational approach to three-dimensional elasticity solutions of laminated composite plates. J Appl Mech ASME 1992;59:166-75. 
[35] Bognet B, Bordeu F, Chinesta F, Leygue A, Poitou A. Advanced simulation of models defined in plate geometries: $3 \mathrm{~d}$ solutions with $2 \mathrm{~d}$ computational complexity. Comput Methods Appl Mech Eng 2012;201-204:1-12. http:/ dx.doi.org/10.1016/i.cma.2011.08.025.

[36] Vidal P, Gallimard L, Polit O. Proper generalized decomposition and layer-wise approach for the modeling of composite plate structures. Int J Solids Struct 2013;50(14-15):2239-50. http://dx.doi.org/10.1016/i.ijsolstr.2013.03.034.

[37] Vidal P, Gallimard L, Polit O. Assessment of a composite beam finite element based on the proper generalized decomposition. Compos Struct 2012;94(5):1900-10. http://dx.doi.org/10.1016/i.compstruct.2011.12.016.

[38] Vidal P, Gallimard L, Polit O. Composite beam finite element based on the proper generalized decomposition. Comput Struct 2012;102-103:76-86. http://dx.doi.org/10.1016/i.compstruc.2012.03.008.
[39] Carrera E. Developments, ideas and evaluations based upon the Reissner's mixed theorem in the modeling of multilayered plates and shells. Appl Mech Rev 2001;54:301-29.

[40] D’Ottavio M, Ballhause D, Wallmersperger T, Kröplin B. Considerations on higher-order finite elements for multilayered plates based on a unified formulation. Comput Struct 2006;84:1222-35.

[41] Tahani M, Nosier A. Free edge stress analysis of general cross-ply composite laminates under extension and thermal loading. Compos Struct 2003:60:91-103.

[42] Gaudenzi P, Mannini A, Carbonaro R. Multi-layer higher-order finite elements for the analysis of free-edge stresses in composite laminates. Int J Numer Methods Eng 1998;41:851-73.

[43] Gu L, Belytschko T. A numerical study of stress singularities in a two-material wedge. Int J Solids Struct 1994;31:865-89. 